\title{
Improved Self-Esteem in Women with Hearing Impairment after Horticultural Therapy and Subjects' Program Preference
}

\author{
Ju Ran Moon ${ }^{1}$ and Yong Kweon Yoo ${ }^{1,2^{*}}$ \\ ${ }^{1}$ Department of Horticultural Science, Mokpo National University, Muan 58554, Korea \\ ${ }^{2}$ The Institute of Natural Resource Development, Mokpo National University, Muan 58554, Korea
}

\section{ABSTRACT}

This study was conducted to determine the effects of horticultural therapy on self-esteem of women with hearing impairment. Ten women with hearing impairment registered in the Mokpo Branch of the Korean Association of the Deaf participated in the horticultural therapy programs (HTP) for self-esteem. The self-esteem scale was used to evaluate the effects of the programs and scores were compared to determine the difference before and after the programs. Self-esteem was improved in all 10 subjects, and its mean value increased with statistical significance from 22.5 points before the programs to 29.8 points after the programs. The programs preferred by women with hearing impairment included 'making a centerpiece using scented candles and flowers', 'packing and planting pot spray chrysanthemum', 'making a topiary', 'planting Hedera helix, and 'planting cyclamen'. Therefore, it was suggested that self-esteem of women with hearing impairment were improved by increasing social and family support, emotional stability, positive feedback, and self-expression through horticultural therapy programs.

Keywords: social and family support, emotional stability, positive evaluation, self-expression

\section{Introduction}

According to the Enforcement Decree and Enforcement Rule of the act on welfare of persons with disabilities in South Korea, persons with hearing impairment are defined as 'persons with hearing loss', with the standard set as 'persons with the hearing loss of each ear at 60 decibel (dB) or higher', 'persons with the hearing loss of one ear at $80 \mathrm{~dB}$ or higher and the other ear at $40 \mathrm{~dB}$ or higher', and 'persons that hear $50 \%$ or less voice articulation of both ears' (Korea Ministry of Government Legislation, 2019). Moreover, the 2017 National Survey on Persons with Disabilities by the Ministry of Health and Welfare showed that there are total 2,668,411 people with disabilities, 282,255 of which are people with hearing impairment and 122,629 are women with hearing impairment, proving that there are the third-biggest number of people with hearing impairment among all people with disabilities, following people with physical disabilities and people with brain lesions (Korea Ministry of Health and Welfare, 2017).

Self-esteem is an evaluative aspect of self-concept that refers to the perceived meaning of one's own value, and it is an emotional assessment of not one's value itself but one's perception on the value (Schunk, 1985). Song (1998) claimed that self-esteem refers to one's notion or attitude, and it is a view of oneself developed by the formation of social relations and belief in individual capabilities. Unlike people without disabilities, people with hearing impairment are likely to be taunted or ostracized by others in childhood or adolescents and face social isolation by being alienated from age-appropriate activities or interactions. These experiences hinder the formation of a healthy and

Received: April 10, 2019, Revised: May 2, 2019, Accepted: July 29, 2019

First author: Ju Ran Moon, ran9591@hanmail.net, (D) https://orcid.org/0000-0001-8761-2808

*Corresponding author: Yong Kweon Yoo, yooyong@mokpo.ac.kr, (D) https://orcid.org/0000-0001-6884-163X 
sound ego, making these persons become more pessimistic about themselves as they grow (Lee, 1996). Even after becoming adults, people with hearing impairment face difficulty accepting spoken language data used by people without hearing impairment. This difficulty in communication of delivering their thoughts to others decreases the ability to empathize with others, causes misunderstanding and conflicts, and frequently reveals negative emotions (Jang et al., 2008). This causes problems in building an emotional bond and interacting with others, making them feel lonely and isolated and forming low self-esteem by exerting negative effects on self-concept, emotional development, and emotional sociality (Jeong, 2014). Moreover, the situation in which they cannot properly perform their social roles causes negative experiences such as frustrations and incompetence, thereby resulting in low self-esteem with a negative ego (Meadow, 1983).

Horticultural therapy increases confidence and desire for achievement among the elderly with dementia or brain diseases through the outputs obtained from horticultural activities. Giving their works to others as a gift or showing them off to others increases confidence and pride, thereby improving self-esteem (Kim and Yoo, 2010; Kong et al., 2015). Moreover, the institutionalized elderly with geriatric illnesses also showed an increase in confidence by creating various horticultural works and outcomes through horticultural therapy. Moreover, by obtaining the opportunity to express negative emotions such as anger, helplessness and sorrow as well as irrational thoughts, they showed improvement in self-esteem by rating themselves positively (Kim et al., 2014; Yoo and Jeong, 2010).

There has rarely been a case in which a horticultural therapy program is carried out for people with hearing impairment, which is because the communication problem makes it difficult to freely build a relationship with those without disabilities, and also because of their negative disposition in which they tend to stay in their own limited social life. Horticultural therapy consists of activities using living plants as the medium and is easy and naturally accessible, thereby more easily applied to the closed world of people with hearing impairment than other alternative health therapies. Therefore, this study is conducted to carry out 10 sessions of the horticultural therapy programs on women with hearing impairment and determine whether the programs are effective in improving the low self-esteem of the subjects and which program they prefer.

\section{Research Methods}

\section{Subjects}

This study was conducted by selecting 20 subjects among women with hearing impairment that belong to the Jeonnam Mokpo Branch of Korea Association of the Deaf who understand the purpose of the horticultural therapy programs and agreed to participate. Before the programs, the horticultural therapist interviewed the subjects (Son et al., 2006) to determine the demographic characteristics, health conditions and disability grade of the subjects. By age, one subject was in $20 \mathrm{~s}$, one in $30 \mathrm{~s}$, five in $50 \mathrm{~s}$, two in $60 \mathrm{~s}$, and one in 70s. As for the disability grade of hearing, eight subjects were Grade 3 and two were Grade 2. Nine subjects except one that is 25 years old and single were married with an average number of children at 2.1. For educational background, seven subjects were uneducated, one was an elementary school graduate, one was a high school graduate and one was a college graduate. All of the subjects used sign language.

\section{Research methods}

\section{Planning}

The purpose of the horticultural therapy programs in this study is set at improving self-esteem, considering the data collected from counseling with the subjects and the therapeutic needs of the relevant staff at the association. This study used a one-group pretest-posttest experimental design that compared the pretest and posttest means of the experimental group.

The programs to improve self-esteem of women with hearing impairment were designed in total 10 sessions with the goal of improving confidence, responsibility, happiness, sociality and emotional stability (Table 1). In Session 1 (packing and planting pot spray chrysanthemum), the subjects were to talk about the fragrance and memories related 
to chrysanthemum while planting them, thereby building a close relationship among them and stimulating the sense of smell that lacks compared to people without disabilities. Session 2 (making a dish garden) was carried out in pairs, and the intention is to improve confidence while making the dish garden and improve the closed sociality by inducing cooperation among the subjects. In Session 3 (making a cell phone rack with pressed flowers), the subjects made cell phone racks necessary for them to participate in video call using sign language, through which their happiness is to improve and their negative ego to become positive. In Session 4 (making a topiary), the subjects made animal-shaped topiary dolls using moss, which is to encourage the subjects to display their individual potential and improve pessimistic confidence. In Session 5 (making a flower basket), the subjects decorated baskets using all kinds of flowers. Since people with hearing impairment perceive information through visual and tactual form than information through hearing, they are to feel the flowers and textures of flowers to stimulate their five senses and improve the low cognitive function. In Session 6 (planting Hedera helix), the subjects adopted and planted various forms of vines, which induced creativity development and allowed them to perceive how important it is to empathize with the general public in a society comprised of various people. Session 7 (making a centerpiece using scented candles and flowers) was to learn how to decorate the table using scented candles and flowers, which is to improve confidence. The candles were lit up to create an emotionally stable mood and have the inner anxiety and fear of the subjects disappear. In Session 8 (making a wreath), the subjects were to make a wreath and hang it on their bedroom door so that they feel the value of their existence at home and feel that they can be loved by their family. In Session 9 (planting cyclamen), the subjects planted the plants that show the sense of season in the pot, encouraging them, who mostly spend time alone and feel isolated and lonely, to feel the pleasure of cultivating plants and emotional stability. Session 10 (making a Christmas tree) encouraged the subjects to decorate a Christmas tree using various ornaments on an artificial fir tree and pray, which is to help the subjects break free from anxiety of the future and feel hopeful and happy. Moreover, they were to give presentations on how they feel about the program and the

Table 1. Contents and goals of horticultural therapy programs for improving self-esteem

\begin{tabular}{|c|c|c|}
\hline Session & Program & Goal \\
\hline 1 & $\begin{array}{l}\text { Packing and planting pot spray chrysanthemums } \\
\text { in pots }\end{array}$ & $\begin{array}{l}\text { Olfactory stimulation and building rapport between subjects and therapist } \\
\text { through planting chrysanthemums }\end{array}$ \\
\hline 2 & Making a dish garden & $\begin{array}{l}\text { Sociality improvement and increasing confidence through cultivating and } \\
\text { making a dish garden }\end{array}$ \\
\hline 3 & Making a cell phone holder with pressed flowers & $\begin{array}{l}\text { Inducement of positive self-image and promoting happiness through making a } \\
\text { cell phone holder for subjects' video call }\end{array}$ \\
\hline 4 & Making a topiary & $\begin{array}{l}\text { Finding potential and improving confidence in subjects through completing } \\
\text { topiary work }\end{array}$ \\
\hline 5 & Making a flower basket & $\begin{array}{l}\text { Development of cognitive and sensory function with seonsory stimuli such as } \\
\text { color, texture, and scent of flowers }\end{array}$ \\
\hline 6 & Planting Hedera helix & $\begin{array}{l}\text { Development of empathic ability and creativity by training vine plants in } \\
\text { various forms }\end{array}$ \\
\hline 7 & $\begin{array}{l}\text { Making a centerpiece using a scented candle and } \\
\text { flowers }\end{array}$ & $\begin{array}{l}\text { Inducement of emotional stability and formation of self-esteem through } \\
\text { learning the decoration technique of scented candle and flowers }\end{array}$ \\
\hline 8 & Making a wreath & $\begin{array}{l}\text { Increasing self-worth and confidence as a family member through the creation } \\
\text { of a wreath that can be hung on your own door }\end{array}$ \\
\hline 9 & Planting cyclamen & $\begin{array}{l}\text { Inducement of emotional stability and pleasure of parenting through planting } \\
\text { and managing seasonal plants }\end{array}$ \\
\hline 10 & Decorating a Christmas tree & $\begin{array}{l}\text { Promoting hope and happiness and resolving anxiety about the future through } \\
\text { prayer after decorating a Christmas tree }\end{array}$ \\
\hline
\end{tabular}


intention for making each work before the end of each session, which is to promote self-expression skills (Table 1).

\section{Implementation}

The horticultural therapy programs to improve self-esteem were carried out once a week, 2 hours each from September 27 to November 29 at an education room of the Korea Association of the Deaf Mokpo Branch. The horticultural therapy team was comprised of one main therapist that obtained the license of Horticultural Therapist Registered-Grade I by Korean Horticultural Therapy Association, one assistant therapist that completed the Horticultural Therapist Program at the Mokpo National University Lifelong Education Center, and one sign language interpreter.

Before implementing the programs, the subjects watched an hour of audiovisual materials to help promote their visual understanding of the program each session, which was comprised of 10 minutes of introduction, 40 minutes of development and 10 minutes of wrap-up. In the introduction stage, the subjects spent some time building a relationship with other subjects or with the horticultural therapists. They were also to express how they feel about the program's materials and contents to stimulate their interest. In the development stage, there was therapeutic intervention according to the goal of horticultural therapy while doing the programs planned for each session, and the subjects were to complete their outputs with therapeutic intervention (Kim et al., 2014; Moon and Yoo, 2019). In the wrap-up stage, they were to present in sign language what they intended and felt about the works they produced and spent time to wrap-up and clean up.

Before the programs, the main therapist and assistant therapist learned simple sign language to communicate with the subjects, and since the subjects had difficulty concentrating, the assistant therapists and sign language interpreter helped them focus on the programs using sign language. Moreover, the sign language interpreter interpreted the descriptions about the main therapist's program in sign language. The assistant therapists wrote down in text and explained anything that the subjects had difficulty understanding in the programs and helped them perform challenging tasks like cutting stems with flower scissors.

\section{Evaluation}

(1) Measurement of self-esteem

Self-esteem is measured using the self-esteem scale developed by Rosenberg (1965), which is a tool measuring the overall attitudes of individuals toward their values and importance. This tool is comprised of 10 items: five positive and five negative items measuring their values, qualities, sense o failure, abilities, pride, satisfaction and respect. They are rated on a 4-point scale from 'Almost never' (1 point) to 'Always' (4 points), with higher scores indicating higher self-esteem.

\section{(2) Program preference survey}

To determine the preference of the subjects over the programs in each session, the subjects were to rate each program on a scale of 'Good' ( 2 points), 'Neutral' (1 point), and 'Not good' ( 0 point). The scores of each session were added up to obtain the mean score.

\section{Analysis method}

Data measuring self-esteem were statistically analyzed using SPSS Win 21 program. As a result of conducting a normality test with 10 subjects, the significance probability of the Shapiro-Wilk test was 0.10-0.81, thereby showing normal distribution. A paired t-test was conducted to analyze the significant difference before and after the horticultural therapy programs.

\section{Results and Discussion}

\section{Effects of horticultural therapy on self-esteem}

As a result of examining the changes in self-esteem of 10 women with hearing impairment before and after horticultural therapy, it was found that all 10 subjects showed increased scores after the programs (Table 2). Subjects E and $\mathrm{G}$ who had a low self-esteem score of 18 points before therapy showed a significant increase to 28 and 29 points, respectively, after therapy. Moreover, the mean score of self-esteem among women with hearing impairment was 22.5 points before therapy but increased by 7.3 points up 
to 29.8 points after therapy, showing statistical significance as well. The mean score of self-esteem among women with hearing impairment before therapy was 22.5 . which is higher than that among elderly with dementia at 11.0 (Kong et al., 2015) but lower than that among the elderly with visual impairment at 23.5 (Kim et al., 2014) and female elderly with geriatric diseases 24.1 (Jeong et al., 2010), indicating that the self-esteem of the subjects in this study had an issue. Moreover, the scores of self-esteem after therapy was 4.0 higher for the elderly with visual impairment and 1.7 higher for female elderly with geriatric diseases, but it was 7.3 higher for women with hearing impairment in this study, indicating that the programs in this study were effective.

Self-esteem is highly correlated with social support; people with low social support show low self-esteem (Jang et al., 2008). Social support indicates assistance or help for an individual provided by relatives, colleagues and neighbors. People with hearing impairment experience social isolation and feel inferior as they are excluded from interaction with colleagues due to communication issues since childhood and adolescence, thereby having negative self-concept such as lack of teamwork and difficulty in interpersonal relations (Lee, 1996; Murphy and Della Corte, 1990). Horticultural therapy programs increased self-esteem of the institutionalized elderly with dementia as they gave out the works they had made to people around them as a gift and felt proud watching the plants they had planted growing (Kong et al., 2015). In this study as well, the subjects had time to have conversations with other subjects or horticultural therapists in the introduction stage of each session. They shared materials and cooperated with one another in programs such as making a dish garden or a Christmas tree, which resulted in interaction as well as recovery of interpersonal relations as they gave out the works they had made to others as a gift, thereby showing improved social support and self-esteem.

Mulcahy (1998) claimed that lack of communication skills among family and inappropriate bond are factors that have negative effects on building self-esteem of people with hearing impairment. In this study, the subjects made a wreath and hung them on their bedroom doors and took home to pots where they planted Cyclamen and Hedera helix, which helped them create a bond feeling the importance and responsibility of communication and cultivation among the family, thereby having a positive effect on self-esteem.

Moreover, self-esteem of people with hearing impairment also had a high reverse correlation with mental health; those with symptoms such as depression, hostility, fear and anxiety have loser self-esteem (Hong, 2008). Horticultural therapy programs enabled female elderly with geriatric diseases and elderly with visual impairment to gain confidence by completing various works using flowers and improved

Table 2. Changes in self-esteem of women with hearing impairment between pre- and post-horticultural therapy

\begin{tabular}{cccc}
\hline Subject & Pre-horticultural therapy (A) & Post-horticultural therapy (B) & Difference (B-A) \\
\hline A & 21 & 28 & 7 \\
B & 21 & 30 & 9 \\
C & 22 & 30 & 8 \\
D & 27 & 33 & 6 \\
E & 18 & 28 & 10 \\
F & 20 & 25 & 5 \\
G & 18 & 29 & 11 \\
H & 23 & 30 & 7 \\
I & 29 & 34 & 5 \\
J & 26 & 31 & 5 \\
M & $22.5 \pm 3.7$ & $29.8 \pm 2.6$ & $.002^{* *}$ \\
\hline
\end{tabular}

Note. Subjects' score ranges from 10-40.

${ }^{* *} p<.01$ by paired t-test. 
depression as they showed off and gave out their works as a gift, thereby increasing self-esteem (Jeong et al., 2010, Kim et al., 2014). Moreover, aromatherapy and color therapy improve self-esteem by stimulating the senses and relieving stress, anxiety and tension (Kim, 2008). In this study, the horticultural therapy programs on women with hearing impairment promoted happiness by having them make cell phone racks using pressed flowers, improved cognitive functions such as vision and smell by making scented candles and flower decorations, and alleviated depression through emotional stability by having hope for the future as they watch the plants grow, thereby improving self-esteem.

Self-esteem of people with hearing impairment tends to be low because of the negative feedback they receive from others. As they continue receiving negative criticisms, they feel as if they are unworthy and have negative emotions about themselves. Therefore, successful experiences and achievable tasks will have great effects in promoting self-esteem of people with hearing impairment (Kim, 2010). Through the programs in this study, the subjects had successful experiences by planting and cultivating flowers as well as making flower baskets, pressed flower decorations, dish gardens and topiary each session, which would have also made them feel a sense of achievement by decorating their house with their works or giving them out to others as a gift. People with low self-esteem tend not to freely express their thoughts and emotions (Kim, 2011). In this study, the subjects showed an improvement in the ability to express themselves in the process of introducing the intention and feeling about the work they made in each session. Furthermore, their self-esteem also improved significantly by overcoming negative ego with positive feedback and responses from the therapists and other subjects (Table 2).

\section{Preference for horticultural therapy programs}

Fig. 1 shows the results of the preference for programs after 10 sessions to improve self-esteem of women with hearing impairment. There was no statistical difference in the preference among 10 sessions of the programs. The program in Session 7, 'making a centerpiece using a scented candle and flowers', was the program most preferred (1.9 points) by the subjects. The subjects could not only learn

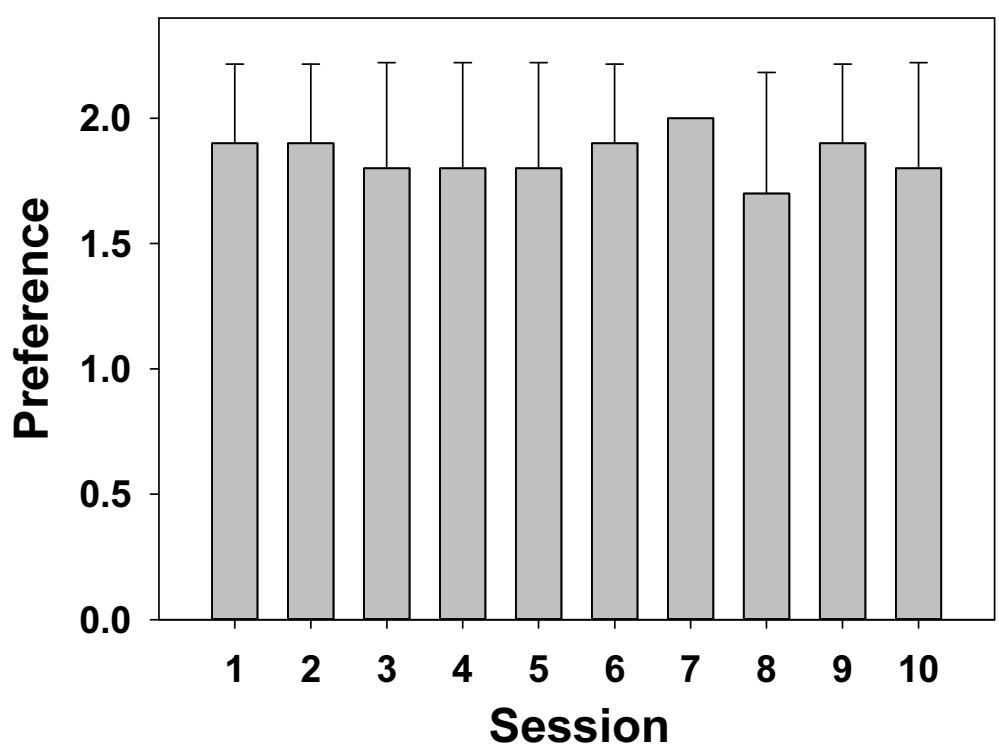

Fig. 1. Preference of horticultural therapy program performed for improving the self-esteem of women with hearing impairment. The content of each session is as follows: 1=packing and planting pot spray chrysanthemums; $2=$ making a dish garden; 3=making a cell phone holder with pressed flowers; 4=making a topiary; $5=$ making a flower basket; 6=planting Hedera helix, 7=making a centerpiece with scented candle and flowers; 8=making a wreath; 9=planting cyclamen; $10=$ decorating a Christmas tree. Bars represent the standard deviation. 
the floral decoration skills by decorating scented candles with colorful flowers but also use these ornaments in real life, thereby increasing confidence. They also showed emotional stability as they smelled the fragrance of the scented candles and flowers and watched the brightly lit up candles. Four programs such as Session 1 'planting and packing the pot spray Chrysanthemum', Session 4 'making a topiary', Session 6 'planting Hedera helix', and Session 9 'planting Cyclamen' were also preferred by the subjects (1.8 points), which are mostly planting programs. This result showed that women with hearing impairment obtained emotional stability by carefully cultivating plants and flowers, proudly expressing in sign language how the plants are growing.

Four programs such as Session 2 'making a dish garden', Session 3 'making a cell phone rack with pressed flowers', Session 5 'making a flower basket', and Session 10 'making a Christmas tree' were relatively not preferred (1.7 points). Session 8 'making a wreath' was most not preferred by the subjects (1.6 points). Difficult, new and diverse horticultural therapy programs may rather increase psychological anxiety for people with visual impairment due to experience and fear about failure (Han et al., 2009; Kim et al., 2014).

The preference survey showed that people with hearing impairment prefer planting and cultivating programs through which they can increase teamwork by helping one another in collaborative work as they plant flowers and plants and find hope about the future by watching the plants grow. Furthermore, they preferred programs that enable them to learn how to make and decorate, and to feel proud that they can do it by watching the results and even give them out as a gift to others. However, 'making a wreath' required skills with greater difficulty than other programs and thus was relatively not preferred due to the anxiety among the subjects that they might fail.

\section{Conclusion}

People with hearing impairment tend to show low self-esteem due to the issue of communication through which they deliver their thoughts to others. In general, they show low self-esteem due to low social support from neighbors or colleagues, low family support, negative feedback from others, and mental health issues like depression and anxiety. Therefore, this study is conducted to determine the effects of horticultural therapy programs, comprised mostly of indoor horticultural cultivation and decorating activities for women with hearing impairment, on self-esteem.

As a result of carrying out total 10 sessions of horticultural therapy programs, the mean score of self-esteem increased significantly after therapy. Among the programs, the subjects showed an increase in confidence and responsibility through planting of Cyclamen, Chrysanthemum, and Hedera helix. Activities of making topiaries, scented candles, flower baskets and wreaths also improved self-esteem by increasing confidence and happiness of the subjects through active communication and gifts to others. Furthermore, the fragrances and colors stimulate the sensory functions and thus improve self-esteem. Olfactory factors like herbs and scented candles in this study as well as visual factors like various colorful flowers increased interest and participation of the subjects, thereby improving their self-esteem. Moreover, their ability to express themselves also improved as they can freely express their thoughts about works and exchange opinions with others during the programs.

The programs highly preferred by women with hearing impairment were 'making a centerpiece using scented candles and flowers', 'planting and packing the pot spray Chrysanthemum', 'making a topiary', 'planting Hedera helix', and 'planting Cyclamen'. Thus, women with hearing impairment prefer programs such as planting that can be used in real life or making decorations with colorful flowers, just like women without impairment (Kim and Yoo, 2005). These programs were effective in improving self-esteem of women with hearing impairment.

In conclusion, the horticultural therapy programs in this study improved social and family support as women with hearing impairment collaborated while working, gave out their completed works to others as a gift, and continued to grow the plants at home, thereby recovering interpersonal and family relations and improving social and family support as a result. Moreover, as they smelled the flowers and scented candles through the programs and completed their works, their confidence and happiness improved. They also found hope for the future as they watched plants grow, 
which may have been effective for emotional stability. Having people with hearing impairment that have great fear about failure complete different works every session, express their emotions about the works, and receive positive feedback from horticultural therapists would have resolved their negative ego. Therefore, the programs in this study significantly improved self-esteem by increasing social and family support for people with hearing impairment, giving emotional stability, and resolving negative ego.

To clearly test the results of this study, it is necessary to compare the control group and experimental group. However, there were not many women that belong to the organization of people with hearing impairment, and thus the research was conducted on only 10 subjects using a one-group pretest-posttest experimental design. Thus, the results may lack representativeness and have limitations in sampling.

\section{References}

Han, S.I., S. Shin, and J.H. Yang. 2009. The photography as a method of self-expression for the visually disabled. AURA 20:29-38.

Hong, J.W. 2008. The effect of self-esteem and social support on the mental health of elderly. Master's thesis, Ewha Womans University, Seoul, Korea.

Jang, S.H., C.S. Kim, and M.R. Kim. 2008. An effect the social support on the self-esteem and life satisfaction in elderly. J. East-West Nurs. Res. 14(2):39-46.

Jeong, H.Y., E.S. Lee, and Y.K. Yoo. 2010. Effects of horticultural therapy on the depression and self-esteem in old woman of day-care center. J. Korean Soc. People Plants Environ. 13(6):53-61.

Jeong, S.W. 2014. The prospective effect of acceptance of disability on self-esteem of persons with hearing impairments. Disabil. Employ. 24(1):167-197.

Kim, H.S. 2008. Effects of aromatherapy and hand massage on stress, depression, and sleep of the institutionalized elderly. Master's thesis, Kongju National University, Kongju, Korea.

Kim, H.S. and Y.K. Yoo. 2005. Effects of horticultural therapy using the press flower on the powerlessness and interpersonal relationship in woman schizophrenia patients. J. Korean Soc. Plants People Environ. 8(1):32-37.

Kim, M.H. 2010. A study of effect dance education has on self-esteem of students with hearing impairments. Master's thesis, Sungkyunkwan University, Seoul, Korea.

Kim, S.Y. 2011. A study on teaching artistic self-expression for enhancing the self-esteem. Master's thesis, Korea National University of Education, Cheongju, Korea.

Kim, Y.S. and Y.K. Yoo. 2010. Effects of horticultural therapy on the self-esteem and emotion in older adult with brain lesion. J. Korean Soc. People Plants Environ. 13(2):1-6.

Kim, M.J., I. Kim, N. Lee, K.Y. Huh, and K.O. Choi. 2014. Effects of horticultural therapy on depression and self-esteem of elderly visual disabilities. J. Korean Soc. People Plants Environ. 17(6):433-440. https://doi.org/10.11628/ksppe.2014.17.6.433

Kong, J.H., S.Y. Yun, and B.J. Choi. 2015. The effects of reminiscence-based horticultural therapy on institutionalized demented elders' self-esteem and quality of life. J. Korean Soc. People Plants Environ. 18(4):305-309. https://doi.org/10.11628/ksppe.2015.18.4.305

Korea Ministry of Government Legislation. 2019. Welfare law for disabled person. Retrieved from http://www.la w.go.kr/lsInfoP.do?lsiSeq=206154\&efYd=20190101\# 0000

Korea Ministry of Health and Welfare. 2017. 2017 Survey of the disabled. Sejong, Korea: Author.

Lee, Y.S. 1996. Influence of self-perception and social support on the school adjustment of adolescents with handicaps: Focus on middle school aged students placed special class of regular schools. Master's thesis, Ewha Woman's University, Seoul, Korea.

Meadow, K.P. 1983. Social adjustment of preschool children: Deaf and hearing, with and without other handicaps. Topics Early Child. Spec. Edu. 3(4):27-40. https://doi.org/10.1177/ 027112148400300407

Moon, J.R. and Y.K. Yoo. 2019. Effects of horticultural therapy on depression and emotional balance of women with hearing impairment. J. People Plants Environ. 
22(2):145-157. https://doi.org/10.11628/ksppe.2019.22.2.145

Mulcahy, R.T.J. 1998. Cognitive self-appraisal of depression and self-concept: Measurement alternatives for evaluating affective states. Doctoral dissertation, Gallaudet University, Washington, DC, USA.

Murphy, L. and S. Della Corte. 1990. School-related stress and the special child. Spec. Parent Spec. Child 6:1-8.

Rosenberg, M. 1965. Society and the adolescent self-image. Princeton, NJ: Princeton University Press.

Schunk, D.H. 1985. Self-efficacy and classroom learning.
Psychol. Sch. 22(2):208-223.

Son, K.C., M.K. Cho, J.E. Song, S.Y. Kim, and S.S. Lee. 2006. Practice of professional horticultural therapy. Seoul, Korea: Koobook.

Song, I.S. 1998. Exploring of self-concept in human. Seoul, Korea: Hakjisa.

Yoo, Y.K. and H.Y. Jeong. 2010. Effect of horticultural therapy program on the depression and self-esteem of the older adult in facilities. J. Korean Soc. People Plants Environ. 13(3):7-15. 